\title{
Experimental study on aqueous phase liquids migration in double-porosity soil under non- isothermal effect using digital image analysis
}

\author{
Loke Kok Foong ${ }^{1, *}$, Ramli $\mathrm{Nazir}^{2}$, Radzuan $\mathrm{Sa}^{\text {'ari }}{ }^{3}$, Erwan Hafizi Kasiman ${ }^{4}$, Noraliani \\ Alias $^{5}$, and Mushairry Mustaffar ${ }^{6}$ \\ ${ }^{1,2}$ Center of Tropical Geoengineering, Faculty of Civil Engineering, Universiti Teknologi Malaysia, \\ Skudai Campus, 81310 Johor Bahru, Johor, Malaysia \\ 1,3,4,5 Department of Water and Environmental Engineering, Faculty of Civil Engineering, Universiti \\ Teknologi Malaysia, Skudai Campus, 81310 Johor Bahru, Johor, Malaysia \\ ${ }^{2,6}$ Department Geotechnical and Transportation, Faculty of Civil Engineering, Universiti Teknologi \\ Malaysia, Skudai Campus, 81310 Johor Bahru, Johor, Malaysia
}

\begin{abstract}
Aqueous phase liquid (APLs) leakage and spillage into the subsurface system, leading to groundwater contamination is an issue that needs to be addressed. This paper aims to investigate the APLs migration characteristics in fractured non-isothermal double-porosity soil. A laboratory experiment was conducted to observe and monitor the characteristics of the soil structure and APLs migration in heated deformable double-porosity soil using digital image processing technique. The results show rapid liquid migration for the fractured soil samples. The time taken for the liquid to migrate under the application of heat is less for sample with low moisture content due to faster dry off and rapid evaporation. It can be concluded that APLs migration under vibration and non-isothermal effect is highly influenced by the soil sample structure, the soil fractured pattern, the soil water content, and the applied heat in the soil.
\end{abstract}

\section{Introduction}

With an increase in global populations, groundwater has become one of the world most extracted natural resources. The current groundwater withdrawal rates is estimated at 982 $\mathrm{km}^{3}$ per year [1]. Although groundwater is part of freshwater resources that occurs naturally, excessive withdrawal has put this finite resource below sustainable levels, where naturally occurring water that can be renewable on the earth surface, but finite resource as groundwater in aquifers, while it's getting limited as usage around the world exceeds sustainable levels [2]. Furthermore, due to climate change and increased occurrence of natural disaster that lead to groundwater pollution, negative impact on human health and geo-environment is unavoidable [3,4]. These occurrences have drawn attention to the significance of vibration, groundwater contamination and liquid migration effect on non-

* Corresponding author: edwinloke84@yahoo.com 
isothermal double-porosity subsurface system. These problems need to be addressed to ensure the sustainability of geo-environmental and groundwater utilization. This problem becomes more complex when the surface or subsurface is subjected to earthquake vibration leading to underground storage tanks leakage and migration of harmful liquids into the groundwater network [5]. Earthquake leads to fractured and unstable soil structure [6]. The changes in soil structure and rock micro crack has significant influence on the soil mechanical behaviour [7]. This also changes the hydraulic conductivity of the soil which has substantial effect of groundwater production [8] as fractured soil has low shear strength but high hydraulic conductivity [9]. The behaviour of liquid migration into the subsurface system become increasing complex if the fractured soil has double-porosity feature and is affected by temperature difference. Soil that displays two distinct scales of porosity, macro and micro pores, are called 'double-porosity soil' that appear different characteristic of pore sizes [10,11]. Masciopinto et al. [12] demonstrated that fractured porosity formations were characterized by water-bearing formations where groundwater flows along the fissures and fractures in the solid rock. The fractures are usually caused by rock mass breakage due to tectonic forces. The heat (non-isothermal) imposed to the soil may influence the liquid migration due to changes in the liquid properties, such as viscosity and density, with temperature [13].

Therefore, this study applied the model concept of fractured double-porosity under nonisothermal in laboratory with the soil that overlaps the three continuums, which consist of fracture porosity, primary porosity, and secondary porosity features as developed by Loke et al. [5]. Image analysis, a simple but powerful method has been used to investigate complicated contaminants migration and liquid saturation rate [14]. Maas and Hampel [15] reported that, image analysis technique in the field of civil engineering has been applied to the study of flow movement in boundary layers and liquid migration of small properties, which specific to the propagation of structure crack extension. Digital image analysis method has been used to capture and analyse liquid migration in soil under laboratory condition by Alazaiza et al. [16]. As the porosity and fractured soils are difficult to observe physically, digital image processing techniques provide an attractive for the study of liquid migration in fractured double-porosity soil. This technique is used in this study to investigate the aqueous phase liquid (APL) migration in fractured double-porosity soil under non-isothermal condition with the aims to provide better insight to the problem.

\section{Experimental materials and methods}

This section discusses the fractured double-porosity soil preparation, non-isothermal experiment setup procedure, and digital image processing setup used in this study.

\subsection{Fracture double-porosity soil preparation}

The available commercial Kaolin soil S300 was utilized as the soil sample to produce double-porosity soil in this experiment. Based on BS 1377-2: 1990 and BS 1377-5: 1990 tests, the Kaolin soil has the following properties, liquid limit $=41 \%$, plastic limit $=27.5 \%$, plasticity index $=13.5 \%$, particle density $=2.65 \mathrm{Mg} / \mathrm{m}^{3}$, particle size distribution $=(2 \%$ sand and $97 \%$ fine, less than $0.06 \mathrm{~mm})$, and falling head permeability test $\left(\mathrm{K}_{\text {average }}\right)=5.42 \mathrm{x}$ $10^{-9} \mathrm{~m} / \mathrm{s}$. Based on the value of Atterberg limits and particle size distribution. The kaolin soil was classified under the Unified Soil Classification System as clay with low plasticity (CL). The aggregated soil was prepared on the method proposed by Bagherieh et al. [17]. The dried kaolin powder was first mixed with water to obtain a sample with moisture content of $25 \%$ and $30 \%$ for experiments 1 and 2, respectively. Two different moisture 
content soils were considered in this study to investigate their role in liquid migration processes [18]. These moisture contents were selected based on the moulding ability of the kaolin soil mixture and liquid limit. The kaolin granules started to disintegrate and fail to form kaolin aggregates when the moisture content exceed $35 \%$, on the other hand, if the moisture content is less than $25 \%$, the kaolin granules become too dry and crumbly $[19,20]$.

Water was poured at a constant rate during mixing of the dried kaolin powder to control moisture content within the mixture. Afterward, the mixtures were placed in a plastic container and kept at room temperature for a minimum of 24 hours to allow water content to reach equilibrium. The mixtures were then sieved through a $2.36 \mathrm{~mm}$ sieve to create double-porosity structure. Next, the kaolin granules were placed in an acrylic circular soil column and compressed to a sample height of $100 \mathrm{~mm}$ with 1 bar of pressure. The compression height was selected to ensure uniformity throughout the soil sample depth [21]. The preparation of double-porosity kaolin soil samples are shown in Figure 1.

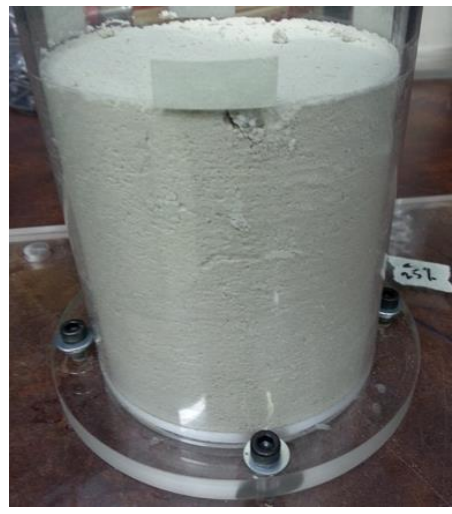

(a) Sample 1 - Double-porosity soil $(25 \% \mathrm{~m} / \mathrm{c})$

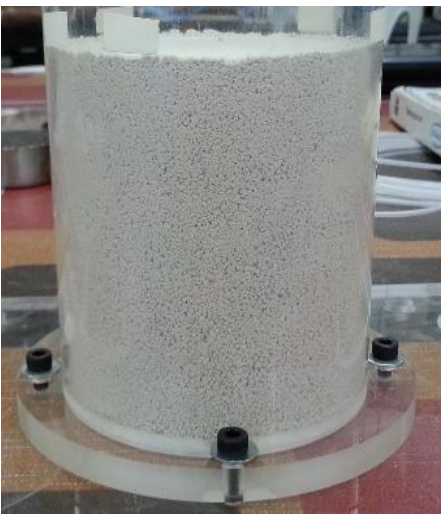

(b) Sample 2 - Double-porosity soil $(30 \% \mathrm{~m} / \mathrm{c})$

Fig. 1. The prepared double-porosity soil sample

The experiments were undertaken in acrylic circular soil column as shown in Figure 2 with a sealed base having height and diameter of $150 \mathrm{~mm}$ and $100 \mathrm{~mm}$, respectively. The acrylic soil column with triangle base plate was perfectly fixed and bolted on the vibration table to prevent backlash during the vibration process. The vibration table frequencies were calibrated using a high sensitivity accelerometer and Dewesoft Sirius System data-logger to ensure it is functioning well. The vibration table vibrates in the vertical direction.

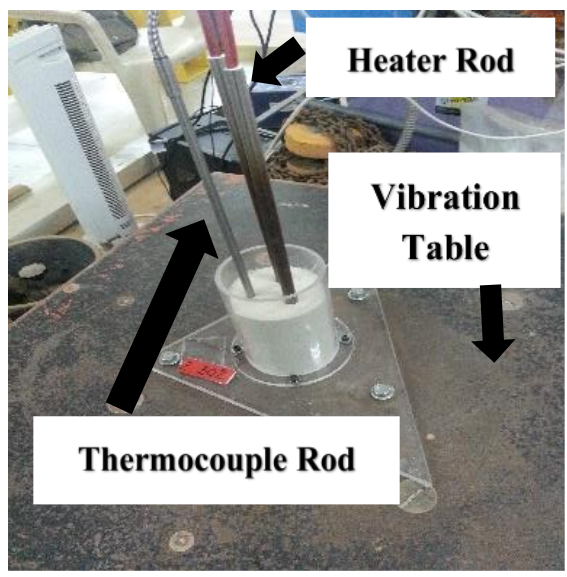

Fig. 2. The thermocouple and heater setup in double-porosity soil 
To apply heat (non-isothermal) to the double-porosity soil, two rods of heater and one rod of thermocouple were installed at the centre of the soil as shown in Figure 2. The full setup of the vibration table for experiment, first proposed by Loke et al. [6], is shown in Figure 3. The vibration frequency of the vibration table was set to $0.98 \mathrm{~Hz}$ for a period of 60 seconds has been applied as reported elsewhere by Loke et al. [6]. The effect of the fractured double-porosity soil sample is shown in Figure 4. The fracturing of the top soil surface is clearly evident as the consequences of the vibration applied to the doubleporosity soil.

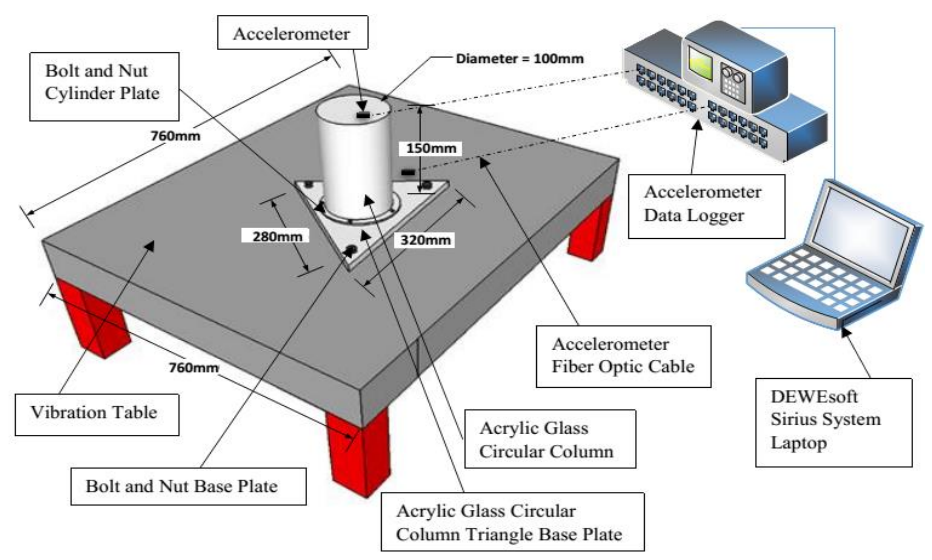

Fig. 3. 3D diagram of vibration table setup [6]

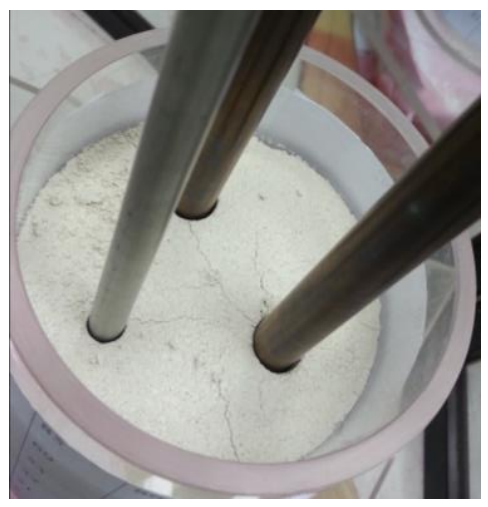

Fig. 4. Fractured double-porosity soil sample after vibration is applied

\subsection{Non-isothermal experiment setup procedure}

After the soil fracturing process, the non-isothermal experiment was setup as shown in Figure 5 for the APL migration image acquisition. The adjustable heater machine was used to generate heat at a specific temperature. The adjustable heater machine was connected to two heater rods to apply heat throughout the soil column. A thermocouple rod was also installed in the soil to check the soil temperature directly. After the cable of heater and thermocouple has been installed in the heater machine, push the button to switch on the heater to impose heat to the soil sample for create the simulation of soil sample with nonisothermal condition.

A digital camera (NIKON D90 DSLR) used as the image acquisition device to record the APL migration. The camera has a medium size image format of 3216 x 2136 pixels 
with a sensor size of $23.6 \mathrm{~mm} \times 15.8 \mathrm{~mm}$. The digital camera setting during the experiments was operated at a minimum shutter speed of 1/640 second, ISO sensitivity set at ISO-2500 and aperture fixed at f/5.6. A V shape mirror arrangement was used to allow the whole soil column surface to be captured in a single shot as shown in Figure 5. The snapshot of the APL migration over the whole soil column circumference can be captured at a prescribed time instances. A 2600 lumens/watt light was installed above the soil column to provide adequate light during image acquisition.

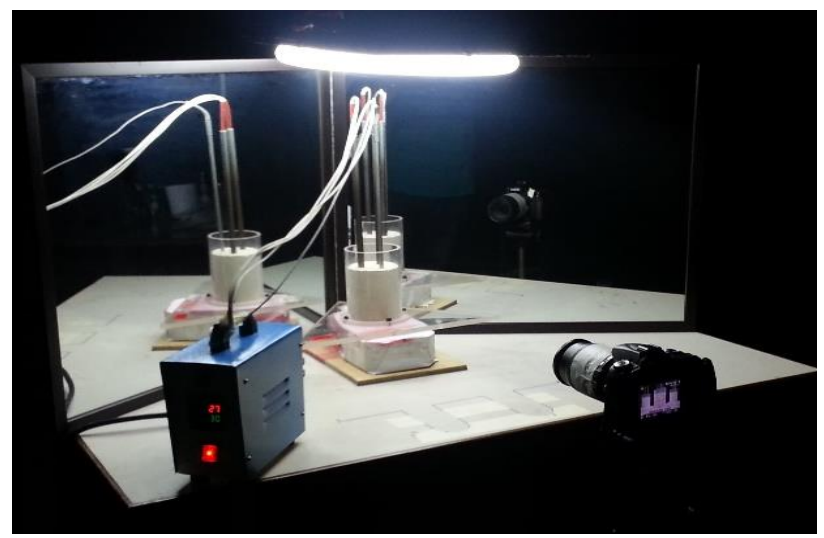

Fig. 5. Digital image acquisition experiment setup with $\mathrm{V}$ shape mirror and non-isothermal machine

A white paper with pre-drawn gridline $(20 \mathrm{~mm} \times 20 \mathrm{~mm})$ was first sheathed onto the soil column and act as a control point on the reference image. Once the reference image was taken, the pre-drawn gridline paper was removed from the soil column. The adjustable heater machine starts heating up the soil to 30 Degrees Celsius. The values were calibrated by the thermocouple. The experiment started with instantaneously pouring of the APL onto the top centre of the fractured soil sample in circular acrylic soil column. The APL used in both samples 1 and 2 is $70 \mathrm{ml}$ dyed water (inorganic compounds) with miscible phase. After the APL had covered the whole top surface area of the fractured double-porosity soil sample, the first snapshot of the APL migration was taken. The subsequent snapshots were taken at a specific time interval to capture the APL migration for the both experiments based on the total completed liquid migration times. Sample 1 was recorded for a total of 62 minutes, while sample 2 was recorded for 90 minutes to ensure the complete migration of APL. Using image acquisition frequency given in Table 1, a total of 119 images and 117 images were captured for samples 1 and 2, respectively.

Table 1. Image acquisition frequency

\begin{tabular}{|c|c|c|}
\hline \multirow{2}{*}{ Duration (minute) } & \multicolumn{2}{|c|}{ FREQUENCY INTERVAL (s) } \\
\cline { 2 - 3 } & Sample 1 & Sample 2 \\
\hline $0-2$ & $3 \mathrm{~s}$ & $3 \mathrm{~s}$ \\
\hline $2-4$ & $5 \mathrm{~s}$ & $5 \mathrm{~s}$ \\
\hline $4-6$ & $10 \mathrm{~s}$ & $10 \mathrm{~s}$ \\
\hline $6-8$ & $15 \mathrm{~s}$ & $15 \mathrm{~s}$ \\
\hline $8-9$ & $20 \mathrm{~s}$ & $20 \mathrm{~s}$ \\
\hline $9-10$ & $30 \mathrm{~s}$ & $30 \mathrm{~s}$ \\
\hline $10-20$ & $60 \mathrm{~s}$ & $60 \mathrm{~s}$ \\
\hline $20-30$ & $60 \mathrm{~s}$ & $60 \mathrm{~s}$ \\
\hline $30-60$ & $300 \mathrm{~s}$ & $300 \mathrm{~s}$ \\
\hline $60-70$ & $600 \mathrm{~s}$ & $600 \mathrm{~s}$ \\
\hline $70-80$ & - & $600 \mathrm{~s}$ \\
\hline $80-90$ & - & $600 \mathrm{~s}$ \\
\hline
\end{tabular}




\subsection{Digital image processing setup procedure}

A digital image processing technique (DIPT), a technique that uses computer algorithms to perform image processing on the images that have been digitally captured was used. The images were captured in colour and saved in the JPEG format. The recorded images then were transferred from digital camera to a computer for further image processing using Matlab routine and Surfer Software version 10. The Surfer software was used to digitize the control point from the reference image and to generate plot the APL migration using Hue Saturation Intensity (HSI) value. The flow chart of the DIPT is shown in Figure 6.

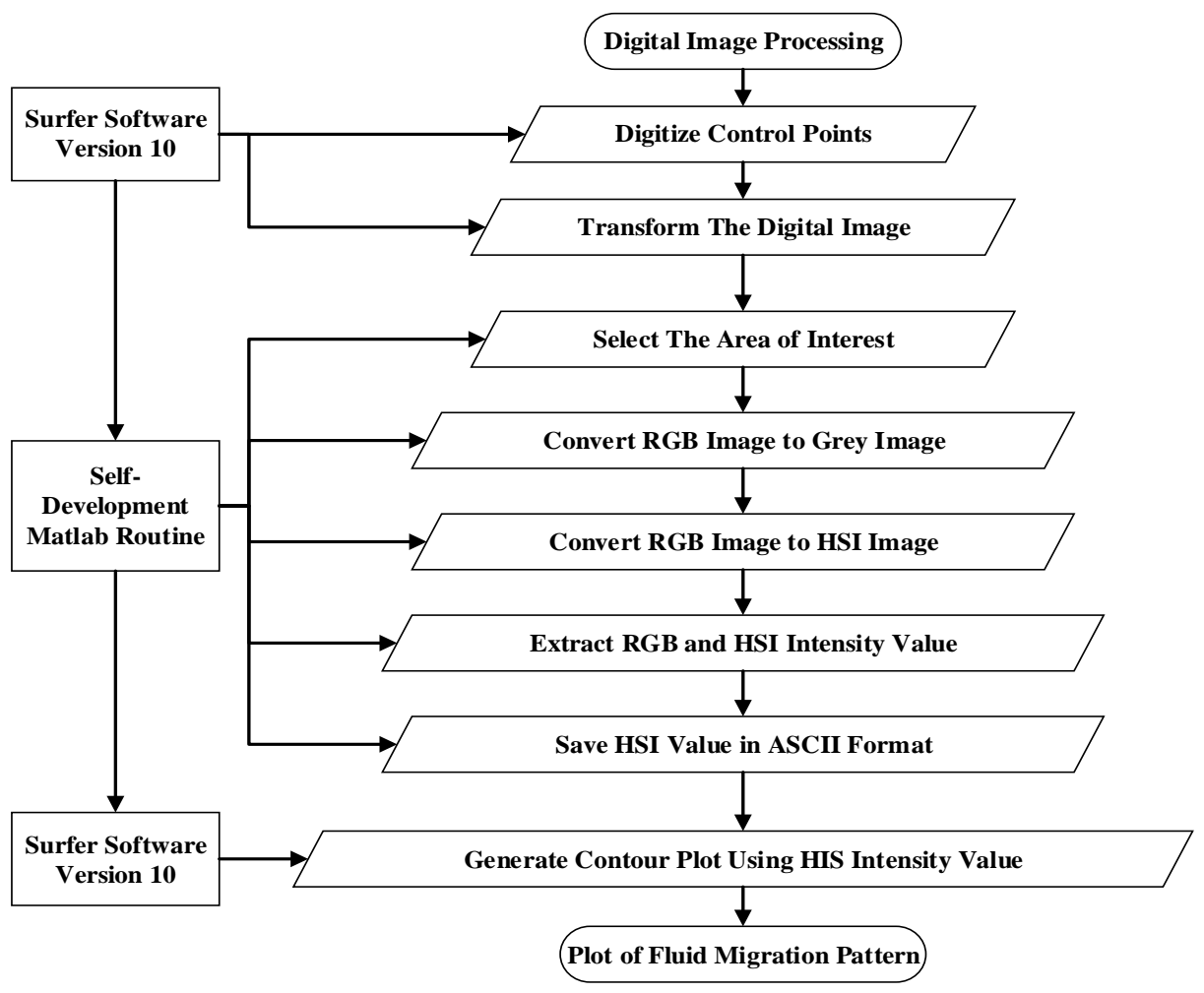

Fig. 6. The digital image processing technique flow chart

The digitization of the control points of area of interest on the reference image is carried out to extract the coordinates of the control points on the circumference surface of the soil column, as shown in Figure 7. Area of interest refers to pre-determined migration boundary area (front image and V shape refection image) for the experiments 1 and 2 that contained the dyed water. Matlab routine was then used to convert area of interest into RGB and HSI image format. The RGB and HSI intensity values from the image were extracted and saved in ASCII format. Matlab routine was used to loop the subsequent digital image three times to extract and save the intensity values for all three section areas of interest (front image and $\mathrm{V}$ shape mirror refection image) of the acrylic soil column. Lastly, a contour plot pattern of the migration pattern of APL in fracture double-porosity under non-isothermal condition using HSI value was generated. The HSI contour plots that describe the APL migration provide useful information such as the migration pattern and flow rate. 


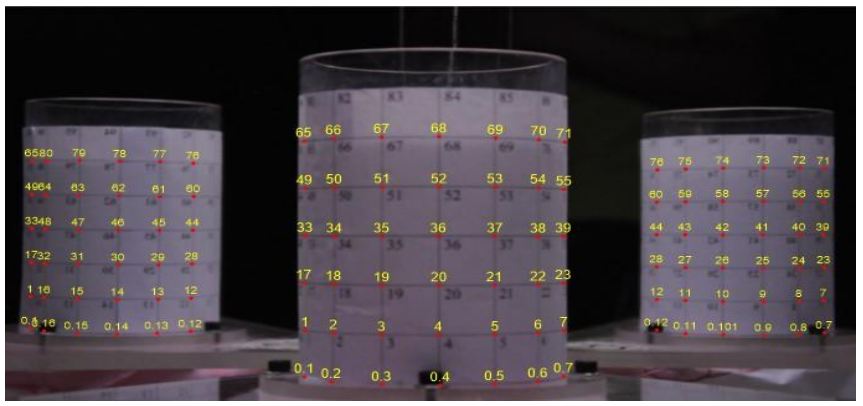

Fig. 7. Control point digitization for area of interest

\section{Results and discussion}

The results after the APL migration process for the top soil surface was divided by actual size measurement of the column circumference to visualize the crack position for experiments 1 and 2 as shown in Figure 8.

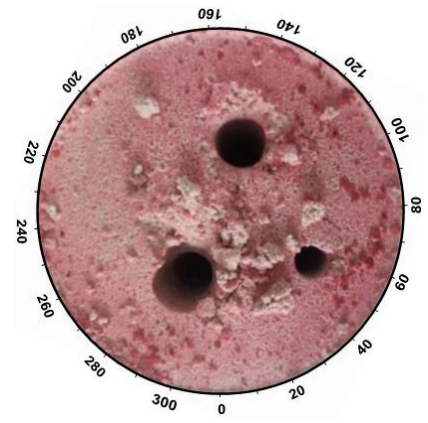

(a) Soil sample 1 with $25 \%$ moisture content

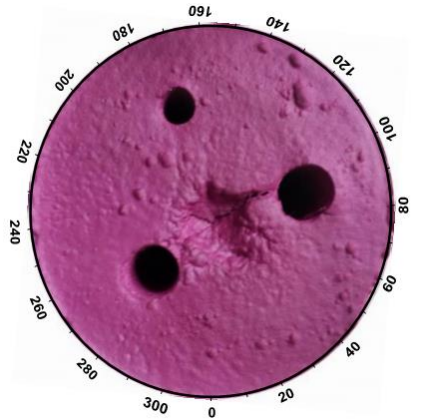

(b) Soil sample 2 with $30 \%$ moisture content

Fig. 8. APL migrated soil surface with measurement of actual column circumference zone

Based on the observation Figure 8, it is clear that the fracture pattern and soil colour are different for both samples. The soil colour for sample 2 is darker because the soil is wetter with higher moisture content as compared to soil sample 1. The downward migration pattern of HSI contour plot of the APL in the non-isothermal fractured double-porosity soil sample with $25 \%$ and $30 \%$ moisture content for samples 1 and 2, respectively, are shown in Figure 9. Samples 1 and 2 used 70ml dyed APL. It was poured instantaneously on top centre of the soil sample surface by using a glass funnel. This is to ensure that the dyed APL penetrated consistently. At time, $t=6$ minutes (Figure 9a), the HSI plots are clearly visible in two-dimensional shape when using the HSI plot to assemble the curve joins the left and right-hand boundary forming a circular shape similar to whole soil column round shape reminiscent. However, the fluid migration in the acrylic soil column was actually one-dimensional.

In non-isothermal soil sample 1, the selected HSI plots of dyed APL migration at interval of such as 0.5, 6, 36, and 62 minutes, respectively, can be seen in Figure 9a. Based on the HSI intensity contour plot result, the flow of dyed APL migration was not uniform because rapid migration occurred in the fractured soil surface condition compared to other locations that did not display cracked soil surface as shown in Figure 8a. Observation during APL migration process, the dyed water completely migrated on the whole top soil surface area into the non-isothermal fractured soil sample 1, which took about 12 minutes. At 0.5 minutes after the commencement of the experiment, the dyed APL migration 
reached only $1 \%$ through of the test sample height. It is due to the non-isothermal heat imposed to the double-porosity soil, which slow down the migration flow. The deepest APL migration depth along the soil column was $23 \mathrm{~mm}$ out of $100 \mathrm{~mm}$ soil sample column height. Meanwhile, the duration for dyed APL migration from the top surface to the stop point was 62 minutes and further monitoring at 90 minutes showed no changes in the migration pattern. The APL migration stop at $23 \mathrm{~mm}$, because based on the observation of the migration process, the heat imposed to the soil has caused the APL to go through the process of evaporation.
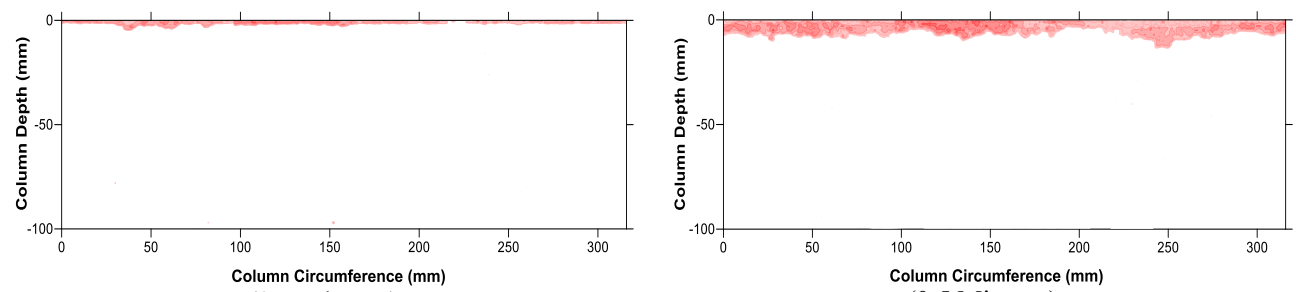

(0.5 Minutes)

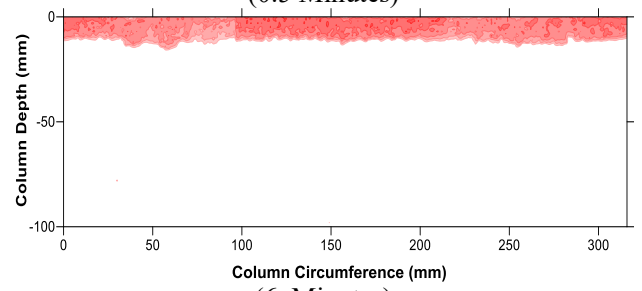

(0.5 Minutes)

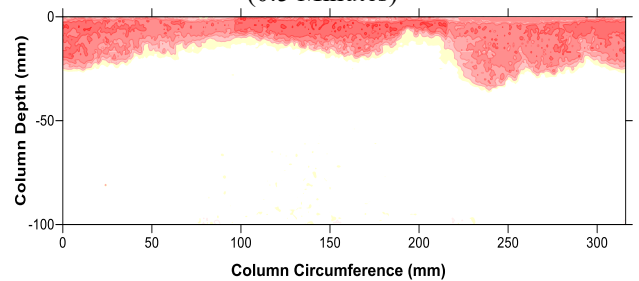

(6 Minutes)

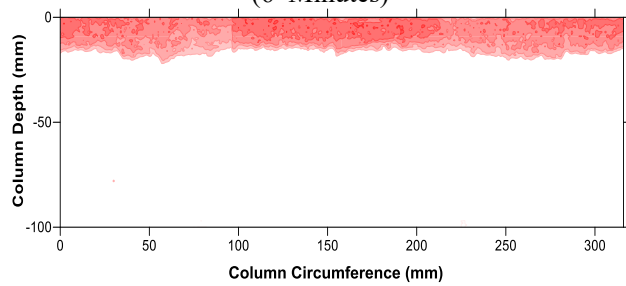

(6 Minutes)

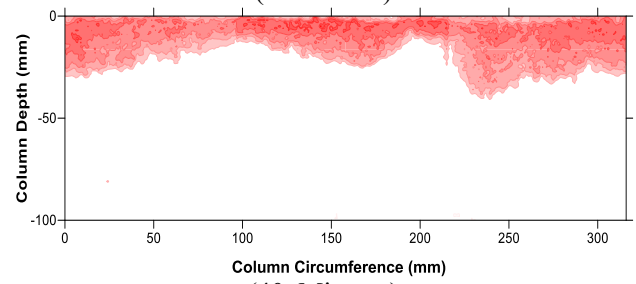

(36 Minutes)

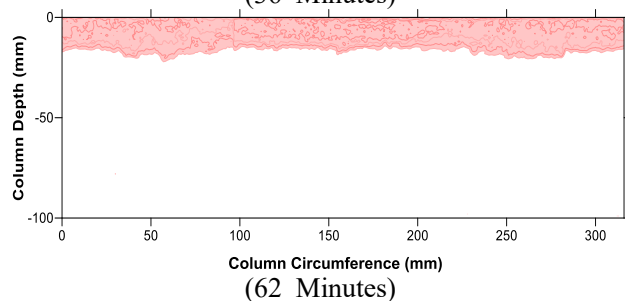

(a) APL migration in sample $1-25 \%$ moisture content

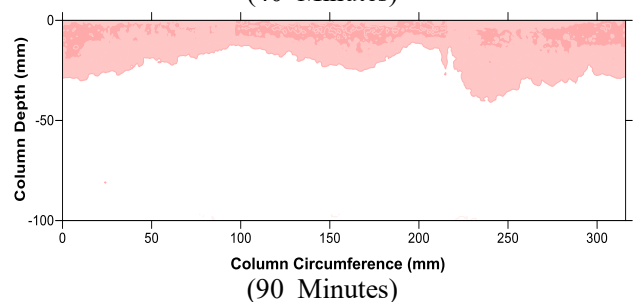

(b) APL migration in sample $2-30 \%$ moisture content

Fig. 9. HSI plots of downward APL migration in fracture double-porosity soil under non-isothermal condition for samples 1 and 2 .

In non-isothermal soil sample 2 , the interval of $0.5,6,40$, and 90 minutes were selected for theAPL migration HSI plot as shown in Figure 9b. For the experiment soil sample 2, the migration pattern bore slightly similar to the result found in experiment soil sample 1 . It occurs since both of the samples were not fully $100 \%$ migrated to the bottom of the soil column. For dyed APL in sample 2 to completely recede from view on the whole top soil surface area into the non-isothermal fractured soil surface of the test took about 25 minutes. During the initial experiment of 0.5 minutes, the dyed water migration just only reached $7 \%$ 
through the test sample height. This is similar happens to sample 1, where the soil sample exposed to heat effect during the migration process and the APL entry pressure was low in the heated soil. Meanwhile, the overall duration for dyed water migration from the top surface to the stop point was 90 minutes and further observation at 120 minutes showed no changes in migration pattern where the deepest dyed APL migration was at $240 \mathrm{~mm}$. It occurs along the $\mathrm{x}$-axis and reached approximately $42 \%$ downward soil column depth.

In previous research, an experiment on toluene migration in double-porosity soil with $25 \%$ and $30 \%$ moisture content and the results have shown the non-aqueous phase liquid (NAPL) migration from top to bottom took about 38 minutes and 4 minutes with fully $100 \%$ NAPL migrated into the soil were conducted by Sa'ari et al. [19] and Ngien et al. [10], respectively. A significant difference was found in this experiment with the result of APL migration from top to the stop point took about 62 minutes and 90 minutes with not fully APL migrated into the soil for $25 \%$ and $30 \%$ respectively. It found that the fact of water viscosity was $0.00089 \mathrm{~kg} /(\mathrm{m} . \mathrm{s})$, while toluene viscosity was $0.00055 \mathrm{~kg} /(\mathrm{m} . \mathrm{s})$, the both viscosity difference of about 38\% [22]. This both experiments showed the migration time was slowed down and not fully migrated because of the water has a higher viscosity compared to toluene, therefore, dyed water caused the high friction and resistance to gradual migration. Both samples were not fully migrated, this could also because the physical bonding between toluene and soil is weaker than water and soil. The physical bonding between toluene and soil was attributed to Van Der Waals Force, which are weaker than hydrogen bonding, and which has stronger physical bonding between water and soil.

The measured value of APL saturation depth as a function of column circumference for every $30 \mathrm{~mm}$ column circumference are shown in Figures 10 and 11 for soil samples 1 and 2, respectively. Based on Figure 10, the fastest and most critical migration downward to a cumulative saturation depth of APL migration occurs in $60 \mathrm{~mm}$ column circumference within 6 minutes as demonstrated by the steepest gradient of the graph lines within that duration. Thereafter 6 minutes, showed a gradual downward decline until the end of the experiment. $270 \mathrm{~mm}$ and $240 \mathrm{~mm}$ column circumference showed the second and third critical rapid infiltration, respectively, within 6 minutes as demonstrated by the sharp gradient of the graph line within that duration and subsequently began to gradually incline horizontally until the end of the experiment. Meanwhile, the rest remaining column circumference positions displayed a slight decrease of APL migration from start until the end of the experiment.

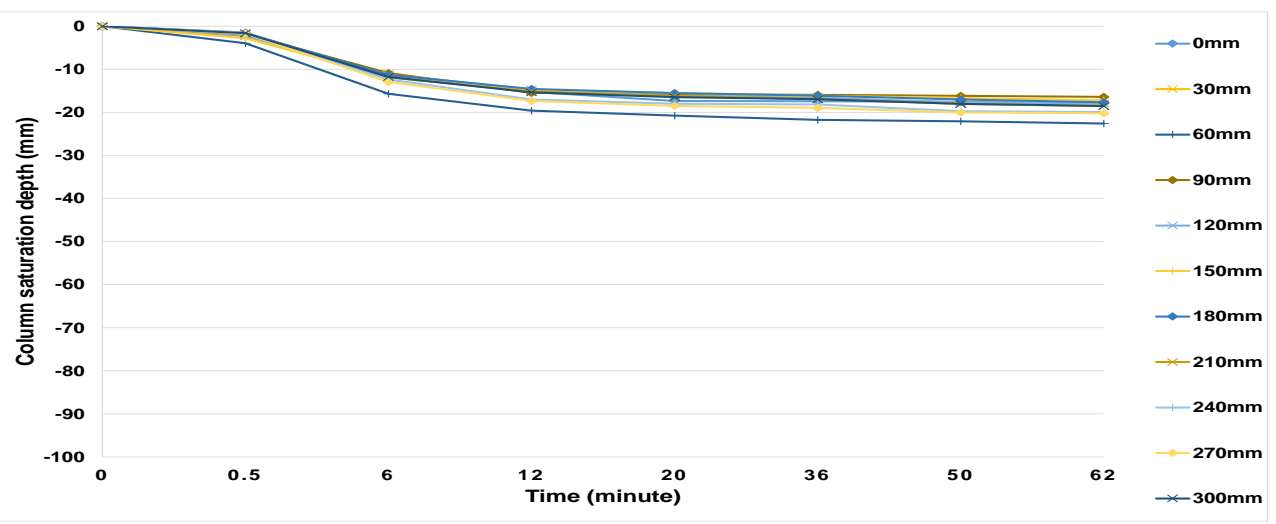

Fig. 10. Measured values of APL saturation depth as a function of time for every interval $30 \mathrm{~mm}$ column circumference zone in soil sample 1

Based on the Figure 11, the cumulative saturation depth of dyed APL migration at $240 \mathrm{~mm}$ column circumference was the fastest critical infiltration within 6 minutes as 
displayed by the sharp steepest gradient of the graph lines within that duration, and after 6 minutes began to slightly move downward until the end of the experiment. At $270 \mathrm{~mm}$ column circumference was the second fastest critical infiltration within 6 minutes as demonstrated by the sharp gradient of the graph line within that duration. At $0 \mathrm{~mm}$ column circumference was the third fastest critical infiltration within 6 minutes as shown by the steep gradient of the graph line and began to gradually incline horizontally until the end of the experiment after 6 minutes. The soil sample 2 displayed that the pattern of APL saturation had the deeper and higher pressure at initial condition of non-isothermal fractured double-porosity soil compared to soil sample 1 because the high moisture and high capillary force occurred at the fracture position at soil sample 2 .

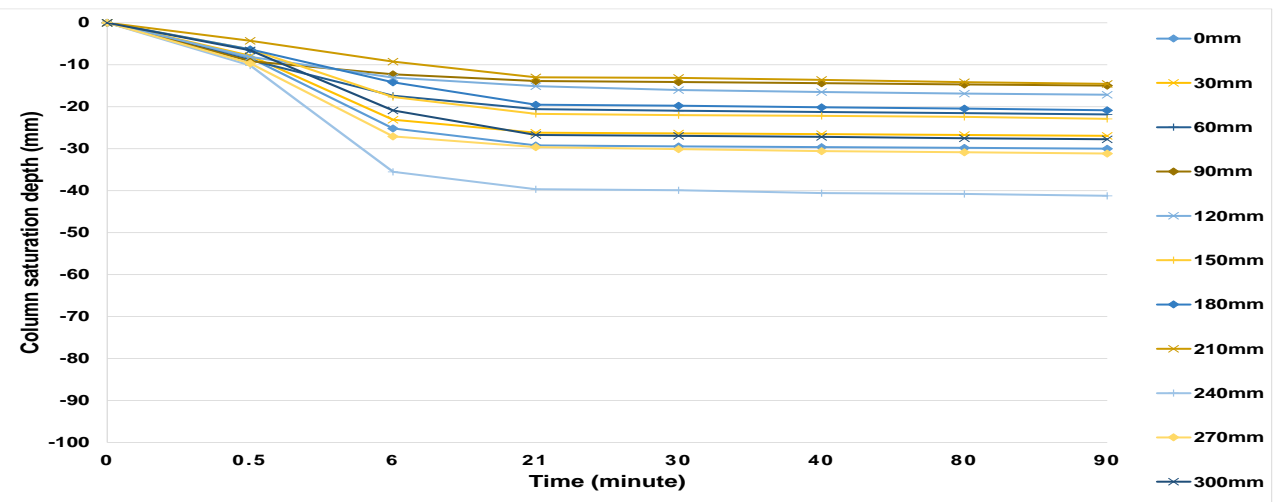

Fig. 11. Measured values of APL saturation depth as a function of time for every interval $30 \mathrm{~mm}$ column circumference zone in soil sample 2

Table 2. APL migration speed rate for every $30 \mathrm{~mm}$ column circumference

\begin{tabular}{|c|c|c|c|c|}
\hline \multirow{3}{*}{$\begin{array}{l}\text { Column } \\
\text { Circumference } \\
\text { Zone }(\mathrm{mm})\end{array}$} & \multicolumn{4}{|c|}{ Non-Isothermal Migration Flow Rate $(\mathrm{mm} / \mathrm{s})$} \\
\hline & \multicolumn{2}{|c|}{$\begin{array}{c}\text { Soil sample } 1 \\
\text { (25\% Moisture Content) }\end{array}$} & \multicolumn{2}{|c|}{$\begin{array}{c}\text { Soil sample } 2 \\
(30 \% \text { Moisture Content })\end{array}$} \\
\hline & $\begin{array}{l}\text { Higher Flow } \\
\text { Between Initial } \\
\text { to } 30 \text { Seconds }\end{array}$ & $\begin{array}{c}\text { Average Flow } \\
\text { for All the Time } \\
\text { Interval }\end{array}$ & $\begin{array}{l}\text { Higher Flow } \\
\text { Between Initial } \\
\text { to } 30 \text { Seconds }\end{array}$ & $\begin{array}{c}\text { Average Flow } \\
\text { for All the Time } \\
\text { Interval }\end{array}$ \\
\hline 0 & 0.05 & 0.01 & 0.31 & 0.05 \\
\hline 30 & 0.07 & 0.02 & 0.26 & 0.04 \\
\hline 60 & 0.13 & 0.04 & 0.30 & 0.04 \\
\hline 90 & 0.06 & 0.01 & 0.30 & 0.04 \\
\hline 120 & 0.08 & 0.02 & 0.27 & 0.04 \\
\hline 150 & 0.08 & 0.02 & 0.21 & 0.04 \\
\hline 180 & 0.05 & 0.01 & 0.21 & 0.04 \\
\hline 210 & 0.06 & 0.02 & 0.14 & 0.02 \\
\hline 240 & 0.09 & 0.03 & 0.34 & 0.06 \\
\hline 270 & 0.10 & 0.03 & 0.32 & 0.05 \\
\hline 300 & 0.05 & 0.01 & 0.22 & 0.04 \\
\hline
\end{tabular}

The calculated migration speed rate for the higher and overall average speed for every $30 \mathrm{~mm}$ column circumference zone was displayed in Table 2. Soil sample 1 shows the higher APL migration speed rate from initial to 30 seconds was at $60 \mathrm{~mm}$ column circumference zone with the migration speed rate of $0.13 \mathrm{~mm} / \mathrm{s}$. Meanwhile, the other high APL migration speed rates occurred at $270 \mathrm{~mm}$ and $240 \mathrm{~mm}$ column circumference with the value of $0.10 \mathrm{~mm} / \mathrm{s}$ and $0.09 \mathrm{~mm} / \mathrm{s}$, respectively. Thus, the overall average dyed APL migration speed rate for non-isothermal fractured double-porosity soil sample 1 is 0.02 
$\mathrm{mm} / \mathrm{s}$. At the $60 \mathrm{~mm}$ column circumference zone there was the highest average APL migration speed rate with $0.04 \mathrm{~mm} / \mathrm{s}$ with the depth of $3 \mathrm{~mm}$ as shown in Figure $9 \mathrm{a}$ with 30 seconds. This could be because the worst non-isothermal fractured soil structure after the vibration was at the position of $60 \mathrm{~mm}$ based on the observation. The overall average dyed APL migration speed rate for fracture soil sample 2 is $0.04 \mathrm{~mm} / \mathrm{s}$. The higher average speed rate occurred at $240 \mathrm{~mm}$ column circumference zone with $0.06 \mathrm{~mm} / \mathrm{s}$ and the deeper migration along the soil column depth at the time between initial to 30 seconds with the depth height of $10 \mathrm{~mm}$. This scenario happened due to the inter-aggregate pore for $30 \%$ moisture content in sample 2 was quite big compared to sample 1 with $25 \%$ moisture content, in which this condition could cause the faster migration in sample 2 but it took longer duration of the migration because the wettability of sample 2 .

\section{Conclusion}

The laboratory experiment on APL migration in non-isothermal fractured doubleporosity soil with $25 \%$ and $30 \%$ moisture content had been carried out. This study was intentionally designed to monitor the dyed APL migration characteristic and pattern in the non-isothermal fractured double-porosity soil placed in circular acrylic soil column model by using digital image processing technique. The laboratory experiment successfully provided the results of the various behaviours and speed rate of dyed APL migration at different moisture content between $25 \%$ and $30 \%$. From the results observed, both experiments indicate that the dyed water migrated slower at the initial stage because the heated soil with the evaporation process made the migration slow down. Both samples were not fully migrated to the bottom of the soil column since the water has a higher viscosity compared to toluene which was conducted by previous researchers. It also due to the physical bonding between toluene and soil attributed by the Van Der Waals Force that are weaker than hydrogen bonding. It has stronger physical bonding between the water and soil. The total migration time for soil sample 1 was shorter compared to soil sample 2, due to the fact that sample 1 is drier in the non-isothermal condition. This will allow the surrounding water to be absorbed, which then resist further infiltration to the bottom of the soil. Soil sample 2 has a faster migration speed rate compared to soil sample 1 due to bigger inter-aggregate pore size which, allow APL flow faster into the non-isothermal fractured double-porosity soil. This phenomenon caused by the capillary force exerted by the dyed APL and high flow water pressure at the condition where the soil samples were fractured. This study indicates that DIPT with HSI plot can provide useful information to understand the non-isothermal APL migration that can be used to identify the remediation method and sustainable groundwater resources.

\section{Acknowledgements}

The authors would like to acknowledge the financial support of this research by Universiti Teknologi Malaysia under GUP Tier 1 vote number Q.J130000.2522.20H53, PY/2016 /06547 and MOHE 4F894. Also, express appreciation to all who are involved in this research. Special thanks to beloved late Dr. Norhan Abd Rahman for his big contribution.

\section{References}

[1] National Ground Water Association, “Defining groundwater 'sustainability' vital to establishing best practices and policy," (Press Release NGWA, ohio, 2016)

[2] S. L. Postel, Entering an Era of Water Scarcity: The Challenges Ahead, Ecol. 
Appl., 10, 4, 941-948, (2000)

[3] V. Muguntan, S. Ruben, S. Lee, Strong earthquake strikes Sabah (The Star Online, Ranau, Sabah, 05-Jun-2015)

[4] Y. A. Razak and M. H. A. Karim, Groundwater in the Malaysian Context, in Groundwater Management in Malaysia -Status and Challenges, Groundwater Colloquium (2009)

[5] K. F. Loke, N. Abd Rahman, R. Nazir, Experimental study on unsaturated doubleporosity soil phenomena under vibration effect, J. Teknol., 4, 65-72, (2017)

[6] K. F. Loke, N. A. Rahman, R. Nazir, R.W. Lewis, Study of aqueous and nonaqueous phase liquid in fractured double-porosity soil using digital image pocessing, Geo. Croatica, 71, 2, 55-64, (2018)

[7] X. Li, C. Qi, Z. Shao, C. Xia, Effect of crack inclination on shear failure of brittle geomaterials under compression, Arab. J. Geosci., 10, 529, (2017)

[8] T. Jiang, J. Zhang, H. Wu, Effect of fracture on the well production in a coalbed methane reservoir, Arab. J. Geosci., 10, 494, (2017)

[9] D. G. Fredlund, S. L. Houston, Q. Nguyen, M. D. Fredlund, Moisture movement through cracked clay soil profiles, Geotech. Geol. Eng., 28, 6, 865-888, (2010).

[10] S. K. Ngien, N. A. Rahman, M. M. Bob, K. Ahmad, R. Sa'ari, R. W. Lewis, Observation of light non-aqueous phase liquid migration in aggregated soil using image analysis, Transp. Porous Media, 92, 1, 83-100, (2011).

[11] A. Carminati, A. Kaestner, P. Lehmann, H. Flühler, Unsaturated water flow across soil aggregate contacts, Adv. Water Resour., 31, 9, 1221-1232, (2008)

[12] C. Masciopinto, M. Benedini, S. Troisi, S. Straface, Conceptual models and field test results in porous and fractured media, in Groundwater Pollution Control, (WIT Press, Southampton, UK, 2001)

[13] J. Grifoll, J. M. Gastó, Y. Cohen, Non-isothermal soil water transport and evaporation, Adv. Water Resour., 28, 11, 1254-1266, (2005)

[14] A. Luciano, P. Viotti, M. P. Papini, Laboratory investigation of DNAPL migration in porous media, J. Hazard. Mater., 176, 1006-1017, (2010)

[15] H. G. Maas, U. Hampel, Photogrammetric techniques in civil engineering material testing \& structure monitoring, Photogramm. Eng. Remote Sens., 72, 39-45, (2006)

[16] M. Y. D. Alazaiza, S. Kong, M. M. Bob, S. A. Kamaruddin, W. Mohd, F. Ishak, Influence of macro-pores on DNAPL migration in double-porosity soil using light transmission visualization method, Transp. Porous Media, 117, 1,103-123, (2017)

[17] A. R. Bagherieh, N. Khalili, G. Habibagahi, A. Ghahramani, Drying response and effective stress in a double porosity aggregated soil, Eng. Geol., 105, 44-50, (2009)

[18] L. Zhuo, D. Han, Q. Dai, Exploration of empirical relationship between surface soil temperature and surface soil moisture over two catchments of contrasting climates and land covers, Arab. J. Geosci., 10, 410, (2017)

[19] R. Sa'ari, N. A. Rahman, N. H. Latif Abdul, Z. M. Yusof, S. K. Ngien, S. A. Kamaruddin, M. Mustaffar, M. A. Hezmi, Application of digital image processing technique in monitoring LNAPL migration in double porosity soil column, J. Teknol., 3, 72, 23-29, (2015)

[20] S. K. Ngien, P. Q. Chin, M. Hasan, M. I. Ali, Image analysis of non-aqueous phase liquid migration in aggregated kaolin, ARPN J. Eng. Appl. Sci., 11, 10, (2016)

[21] K. F. Loke, N. A. Rahman, R. Nazir, R. Sa'ari, M. Mustaffar, Investigation of aqueous and non-aqueous phase liquid migration in double-porosity soil using digital image analysis, Chem. Eng. Trans., 63, 685-690, (2018)

[22] K. R. Assael, M. J., Avelino, H. M. T., Dalaouti, N. K., Fareleira, J. M. N. A. Harris, Reference correlation for the viscosity of liquid toluene from 213 to $373 \mathrm{k}$ at pressures to 250Mpa, Int. J. Thermophys., 22, 3, 789-799, (2001) 